\title{
CLUBE DE LEITURA: ESTRATÉGIA PARA FORMAÇÃO DE LEITORES
}

\author{
READING CLUB: STRATEGY TO READER FORMATION
}

\author{
Thiago Alves Valente* \\ Juliete Rosa Domingos*
}

\begin{abstract}
Resumo: Este trabalho apresenta o processo de implementação de um clube de leitura (clube do livro) como um espaço democrático de formação de leitores, tendo em vista o legítimo encontro entre o leitor e a leitura de literatura, em uma escola no interior paulista. O projeto foi construído com base no trabalho de Maria da Glória Bordini e Vera Teixeira de Aguiar, Literatura: a formação do leitor: alternativas metodológicas (1988), que traz reflexões sobre a leitura literária na escola em práticas da sala de aula; e nos estudos de João Luís Ceccantini (2009) que apresentam a "animação de leitura" como proposição para o trabalho de incentivo à leitura. $\mathrm{O}$ projeto, portanto, veio ao encontro dos princípios discutidos acerca da escolarização adequada da literatura, principalmente a denominada infantojuvenil, visto que, aliando pressupostos teóricos às práticas pedagógicas, buscou sistematizar ações que centralizaram a leitura do texto literário na escola, respeitando sua natureza específica (LAJOLO, 1982, p. 53).
\end{abstract}

Palavras-chave: Animação de leitura. Clube de leitura. Literatura infantil..

\begin{abstract}
This paper presents the process of implementing a reading club (book club) as a democratic space of reader formation, in view of the legitime meeting between the reader and the reading of literature, in a school in a city in the interior of the São Paulo State. The project was built inspired on the work by Maria da Glória Bordini e Vera Teixeira de Aguiar, in the classic Literature: the reader's formation: methodological alternatives (1988), which brings reflections about the reading of literature at school in classroom practices, and in the studies by João Luís Ceccantini (2009), who presents the "reading animation" as proposition for the reading incentive work. The project, therefore, met the principles discussed about the proper schooling of the literature, especially the so-called children's and juvenile literature, since, combining theoretical assumption with the pedagogical practices, sought systematize actions that centralized the reading of the literary text at school, respecting your specify nature (LAJOLO, 1982, p. 53).
\end{abstract}

Keywords: Reading animation. Reading club. Children's literature.

\section{Introdução}

A busca de estratégias para a formação de leitores mobiliza pesquisas nos mais diversos campos do saber. Isso porque, como aponta Cláudio Mello (2011, p.3) amparado em pesquisas de campo, "as crianças chegam à escola gostando de literatura e, mesmo antes de alfabetizadas, são atraídas pela leitura das imagens dos livros. Mas à medida que a escolaridade avança, o interesse pela literatura diminui gradativamente".

Nesse sentido, Rildo Cosson (2006) destaca que há fortes motivações que contribuem para o que se pode entender como a falência do ensino da literatura, dentre elas, a ideia fixa entre alguns, de que a literatura permanece na escola meramente por questões de tradição e do engessamento do currículo; ou que outros textos, não literários, estão sendo mais valorizados por atenderem ao uso pragmático da escrita. A apresentação fragmentada do texto literário, a supervalorização de dados sobre a periodização literária, a não apreciação estética e crítica da obra, mais a leitura literária

\footnotetext{
* Professor Associado. Centro de Letras, Comunicação e Artes (CLCA), Campus Cornélio Procópio (CCP), da Universidade Estadual do Norte do Paraná (UENP). Membro dos grupos de pesquisa Crítica e Recepção Literária (UENP) e Leitura e Literatura na Escola (UNESP). E-mail: kantav2005 @ gmail.com.

* Professora de Língua Portuguesa na rede pública de ensino de São Paulo. Graduação em Letras/Inglês (UENP). Especialização em Estudos Linguísticos e Literários (UENP). Mestrado Profissional PROFLETRAS (UENP).E-mail: julieterd@yahoo.com.br
} 
sob um formato assistemático são condições que também colaboram, segundo o autor, para a literatura permanecer num estado de estagnação, isto é, aquém de seu caráter emancipador e de humanização: "não é possível aceitar que a simples atividade da leitura seja considerada a atividade escolar de leitura literária" (COSSON, 2006, p. 26).

Os problemas, portanto, são bem conhecidos e reiterados em análises sustentadas pela prática cotidiana em sala de aula. Da mesma forma, porém, pode-se apontar o mesmo locus como fonte de respostas para a falência da leitura literária dentre o público escolarizado. Uma das vertentes a serem exploradas encontra-se naquela percepção sobre a "perda do leitor" ao longo do tempo de escolarização - partindo dessa premissa, torna-se relevante perceber como práticas de leitura em diferentes momentos da formação de crianças e jovens contribuem para com a função de levá-los a uma relação positiva com os livros.

Essa perspectiva permite observar, entre outros aspectos, que o caráter lúdico, a brincadeira ou a gratuidade da leitura literária mostram-se mais preponderante à medida que nos aproximamos da primeira infância. Os apelos sensoriais aliados à imaginação sustentam narrativas que, mesmo frágeis em termos estruturais ou semânticos, tendem a envolver toda a turma. Se assim ocorre mesmo quando faltam livros de maior envergadura literária, havendo a oferta de textos de maior valor literário por meio de ações que se pretendam tão ou mais envolventes em termos de mediação de leitura, os resultados podem, por sua vez, configurar realidades mais promissoras. É nesta clave que se insere a proposta dos "clubes de leitura", sendo um deles viabilizado por meio de projeto de mestrado profissional aplicado em uma escola interiorana do Estado de São Paulo.

\title{
2 Os clubes de leitura
}

O comprometimento com a literariedade implica a seleção criteriosa de obras, bem como o estabelecimento de métodos, no contexto escolar, em consonância com a "capacidade de encontrar, por meio da leitura um mundo diverso que atende aos desejos e interesses do leitor de forma criativa e surpreendente, não só pelos temas, mas também pela forma como são apresentados" (FERREIRA, 2009, p. 336). Instigar o interesse pela leitura não deve se confundir com a adesão a uma ideia de "vale tudo", uma aposta inconsequente no paladar pouco experiente de crianças e jovens. Antes, como afirma Eliane Galvão Ferreira:

\begin{abstract}
A literatura almeja sintonizar-se com o tempo a que pertence e com o leitor. Seu processo de construção lúdico e inteligente objetiva a conscientização de seu leitor em relação às descobertas que lhe cabe fazer no mundo. Assim, o imaginário é visto como instrumento de conquista do verdadeiro conhecimento de si mesmo e do mundo em que se vive. Portanto, há necessidade de confronto entre razão e imaginação, para que o leitor possa lidar dialeticamente com essas duas grandes forças de seu ser. A literatura infantil e juvenil contemporânea procura, por meio da autocrítica, da manutenção da autenticidade, da conscientização, da metalinguagem, da dialogia, da intertextualidade, adequar-se às peculiaridades próprias do tipo de leitor a quem se destina. (FERREIRA, 2009, p.114)
\end{abstract}

A ancoragem de reflexões sobre a leitura literária na escola a práticas cotidianas da sala de aula mostra-se no trabalho pioneiro de Maria da Glória Bordini e 
Vera Teixeira de Aguiar, Literatura: a formação do leitor: alternativas metodológicas (1988), sendo reiterado por estudos subsequentes através das últimas décadas, como se lê nos trabalhos de João Luís Ceccantini (2009), para quem a "animação de leitura" experimentada em muitas escolas de ensino infantil revela-se como proposição eficaz para o trabalho de incentivo à leitura literária:

Ao lidar com as questões ligadas aos jovens e, particularmente no que diz respeito à leitura, a escola brasileira não tem sabido encontrar soluções convincentes, de maneira oposta ao que se tem passado em relação à infância, em que, pouco a pouco, se vão acumulando sucessos relevantes. Hoje, sem dúvida, um dos maiores problemas a enfrentar na formação de leitores é o de como dar continuidade às conquistas obtidas junto às crianças, à medida que vão crescendo, de tal modo que continuem sendo leitores fiéis e motivados. (CECCANTINI, 2009, p. 9)

O respeito pela realidade do mundo da leitura escolar atrelado à pertinência de práticas pesquisadas e avaliadas sobretudo pela atuação de grupos de pesquisa em diferentes pontos do território nacional validam o reconhecimento dos "clubes de leitura" como estratégia para formação de leitores. Em seu livro $O$ clube do livro: ser leitor - que diferença faz?, Luzia de Maria (2009) traz reflexões inquietantes sobre a mediação de leitura realizada por um professor leitor e a diferença que isso faz na formação de outros leitores. A autora apresenta, então, discussões sobre a importância da diversidade de obras literárias e da construção do ser leitor. Para isso, relata sua proposta de criação de um clube do livro, o qual foi mantido de 1982 a 1987, para turmas do Ensino Médio no Liceu Nilo Peçanha, em Niterói-RJ, uma escola pública em que lecionava.

Nesse clube, Luzia de Maria atuava como mediadora de leitura: levava inúmeros títulos de diferentes gêneros, temáticas, estilos e autores e apresentava essas obras aos alunos; com isso, a professora inaugurou uma dinâmica em que os alunos podiam indicar livros para comporem o acervo a ser lido e debatido durante os encontros. A ideia era que os alunos se encontrassem semanalmente, em horário extraclasse, para discutirem as leituras que haviam feito.

Por não poder requisitar a compra de livros - daí outro aspecto infelizmente atual no que diz respeito às condições de aquisição de bens culturais por parte do alunado brasileiro - a professora descartou a dinâmica de trabalhar uma única obra lida por todos. Para as atividades iniciais do clube, foram apresentados livros da biblioteca da escola e de sua própria biblioteca particular. As obras eram escolhidas por meio de indicações da professora e/ou pelos próprios alunos. Assim, os livros indicados que caíam no gosto dos alunos passavam a fazer parte da lista de obras a serem lidas por todos.

No intuito de fortalecer a aproximação dos alunos do universo literário, a professora esforçou-se por levar autores cujas obras estavam em circulação entre o grupo a alguns encontros - entre 1982 e 1987, José J. Veiga (1915-1999) e Moacir Lopes (1927-2010) aceitaram todos os convites de Luzia de Maria para dialogarem com os alunos. Dessa maneira, era possível estabelecer um diálogo proveitoso entre o autor, que falava sobre sua obra, e o aluno-leitor, que tinha a oportunidade de emitir opiniões e expressar ideias a partir das leituras realizadas no clube. Luzia de Maria, sobre o resultado dessa estratégia, afirma que "o crescimento daqueles alunos era visível: a expressão oral e a expressão escrita tinham melhoras notáveis, a leitura oferecia a eles 
um passaporte para entrada e circulação no mundo da cultura letrada" (MARIA, 2009, p. 218).

É possível perceber que a configuração do clube, isto é, o formato, a dinâmica estabelecida no decorrer dos encontros, o teor democrático tanto da escolha das obras quanto do espaço cedido para voz de todos os integrantes, foi um dos aspectos marcantes do projeto. A metodologia abarcada de forma sistematizada, somada à liderança de uma professora mediadora convicta de seu papel e da importância dos livros que lia e indicava, contribuiu, substancialmente, para a constituição de uma memória afetiva em relação à leitura de literatura dos alunos.

Sobre isso, Eliane Galvão Ferreira (2009), em sua tese Construindo histórias de leitura: a leitura dialógica enquanto elemento de articulação no interior de uma biblioteca vivida, defende o dimensionamento de práticas democráticas direcionadas para o ensino de literatura em sala de aula. A professora-pesquisadora indicou aos seus alunos três modalidades de leitura de obras literárias, sendo: a leitura opcional; a leitura proposta pela professora; e a leitura opcional entre uma série de obras de autores indicados pela professora. Tais modalidades representaram uma espécie de negociação no universo de leitura do aluno, um equilíbrio entre o "querer" e o "dever", evidenciando a importância da figura do professor mediador para orientação no processo de leitura e, concomitantemente, assegurando o respeito aos gostos e às escolhas dos alunos. Diante da necessidade de catalogar as obras selecionadas, bem como registrar as opiniões dos leitores sobre os textos lidos, criou-se uma ferramenta, denominada "passaporte do leitor", cujo objetivo era "que o aluno acompanhasse ativamente a construção de sua biblioteca vivida" (FERREIRA, 2009, p. 25). Inspirado no passaporte original, o "passaporte do leitor" registraria as viagens realizadas ao longo das diferentes paisagens da narrativa -

Desse modo, o "passaporte" tornou-se um instrumento que apreende,
na construção da história de leitura, esse repertório de obras eleitas
pelos alunos e por mim. Com o "passaporte", pretendia que o aluno
percebesse a produção escrita neste instrumento como um intercâmbio
válido de experiências culturais e de reflexões significativas, pois
capaz de mobilizar o acervo de conhecimentos herdados que ele
possuía, ao mesmo tempo em que lhe permitia efetuar um constante
relacionamento entre o horizonte anterior e o conquistado no presente.
(FERREIRA, 2009, p. 24-25)

Em pesquisa mais recente, com o intuito de "compreender como o processo de múltiplas ações de leitura, articuladas entre si, influenciaria a formação de leitores autônomos" (BALSAN, p. 5, 2018), Silvana Ferreira de Souza Balsan, em tese de doutorado, engajou uma pesquisa-ação envolvendo uma turma de $4^{\circ}$ ano do Ensino Fundamental, em escola da rede pública de Dracena/SP. No texto, a pesquisadora enfatiza três modalidades de ações de leitura dispostas em sala de aula, no decorrer da pesquisa: 1) Oficina de estratégias de leitura; 2) Formação de um clube do livro; e 3) O Baú de Leitura.

Dentre as modalidades de ações de leitura dispostas pela professora em sala de aula, interessa-nos apresentar a formação do Clube do Livro, caracterizado "por proporcionar uma prática de leitura coletiva e o compartilhamento entre todos" (BALSAN, p. 6, 2018) e, ainda, por oportunizar que as discussões fossem "pautadas em um diálogo igualitário entre todos os participantes, de sorte a construir diferentes significados e estimular a participação e o comprometimento dos envolvidos" (BALSAN, p. 119, 2018). 
O clube do livro, implementado pela professora, funcionou entre outubro e novembro de 2015 e contou com a leitura da obra Chapeuzinho Adormecida no País das Maravilhas - Prêmio Jabuti 2006, na categoria infantil - de Flávio de Souza. A dinâmica consistia na realização, pelos alunos, da leitura dos capítulos da obra em casa, conforme indicação do cronograma previamente apresentado pela docente, e, depois, em sala de aula, além de uma conversa sobre a leitura, os discentes realizavam determinadas atividades sobre parte da história anteriormente lida. Vale ressaltar que cada aluno recebeu seu exemplar, na biblioteca da escola, a fim de reafirmar esse espaço como um local de acolhimento e respeito pelas vozes dos leitores.

Partindo de pressupostos acerca da função, contribuição e resultados de clubes de leitura como espaços democráticos para dialogar sobre determinados textos literários, Balsan (2018) destaca:

É através do diálogo e das contribuições de cada participante que ocorre um intercâmbio enriquecedor, o qual permite aprofundar um tema e construir uma comunidade de leitores (COSSON, 2014; SOLÉ, 1998), que parte do princípio educativo de que a aprendizagem é um processo de constituição conjunta de saberes envolvendo todos os participantes, tanto professores quanto alunos, em uma partilha progressiva de conhecimentos e experiências que criam uma cultura, um clima e um espaço no qual o pensamento se edifica. Nesse sentido, o que precisamos manter, nessa ação de leitura, é o protagonismo do estudante, pois a ele cabe o compromisso com o grupo. Com efeito, o Clube do Livro deve ser uma atividade regular, na qual as crianças possam realizar uma permuta de vivências pessoais e expressar impressões atinentes ao texto, por meio da leitura compartilhada. (BALSAN, p. 121, 2018)

Percebe-se, dessa maneira, a preocupação da professora em estabelecer uma relação de mediação democrática frente à obra literária, rompendo com a ideia do professor como dono de uma interpretação uníssona sobre o texto.

A partir da análise dos registros dos discentes, pela escrita ou por meio de desenhos, durante o desenvolvimento das atividades no clube do livro, a pesquisadora observou que, de posicionamentos superficiais, no primeiro momento, acerca do enredo, surgiram, com o desenrolar das discussões entre os leitores mediadas pela professora, posicionamentos mais críticos e com maior iniciativa dos alunos.

Notamos, assim, que as professoras Luzia de Maria, Eliane Galvão Ferreira e Silvana Balsan, todas mediadoras de leitura comprometidas com a formação do leitor literário em seus projetos, registram ações de animação de leitura que proporcionam o contato com obras de qualidade, tendo em vista a formação de um sujeito leitor com autonomia e que, posteriormente, na vida adulta, seja detentor de uma memória afetiva de leitura capaz de transformá-lo no próximo mediador de leitura de literatura em seus espaços sociais. Nessa mesma perspectiva, Oliveira e Valente (2012) ressaltam a relação da memória afetiva com a formação do leitor:

Conforme Ítalo Calvino (2000, p.13), o livro que o leitor torna "seu", pela escolha e uso ao longo do tempo, ocorre somente por meio das leituras desinteressadas. Essas obras passam a constituir sua memória afetiva, atuando como parâmetro de qualidade com o qual defrontam leituras futuras. (OLIVEIRA; VALENTE, 2012, p. 6) 
Tomando por pressupostos as pesquisas dos autores anteriormente comentados, bem como os princípios teóricos comuns a eles, foi proposta, em nível de trabalho de mestrado, uma pesquisa interventiva tendo como ponto central o desenvolvimento de um clube de leitura, somo passamos a relatar.

\section{Reinventando um clube}

O Clube de Leitura "Viver e tecer histórias" surgiu como suporte para o desenvolvimento de ações alternativas e diferenciadas a partir das estratégias de animação de leitura (CECCANTINI, 2009) garantindo espaço (a escola como um todo) e material (obras da literatura infantojuvenil) para que os alunos da E. E. Professora Isabel Cristina Fávaro Palma, do Distrito de Ribeirão Bonito (Tejupá/SP) pudessem se envolver com um processo individual e subjetivo de leitura do texto literário e, consequentemente, dialogar com colegas sobre qualquer aspecto da obra literária que julgassem relevante debater.

Dessa forma, o trabalho intentou contribuir com a ideia de adesão à configuração do papel intrinsecamente cultural desempenhado pela leitura de literatura na escola. Para que fosse possível mudar o latente desencanto que os alunos demonstram em relação aos textos de cunho literário quando ingressam no Ensino Fundamental II, proporcionando a eles novas perspectivas de leitura, optamos por trabalhar com novos textos atrelados à sua vivência e/ou que os desafiassem permitindo que se formasse uma consciência crítica nesses leitores em construção.

A condução do Clube de Leitura "Viver e tecer histórias", como um processo de animação de leitura, de modo geral, foi realizada a partir de dez encontros - de setembro a dezembro de 2018 , em horário contraturno às aulas regulares, seguindo as etapas de:

1. Leitura, com a realização prévia da leitura pelo aluno, em sua casa. A orientação dada ao leitor do clube foi que reservasse um dos momentos de leitura para a compartilhar com alguém de seu núcleo familiar, pedindo inclusive a opinião desse parente sobre o texto lido.

2. Encontros: com a apresentação da obra, iniciando a atividade por meio de uma motivação sensorial. Nessa ocasião, era ofertado ao aluno o espaço para compartilhar suas descobertas, expectativas, frustrações, em relação à obra lida; também foi o momento em que o aluno escolhia o livro para ler durante a semana, até o encontro seguinte.

3. Processo criativo: com a realização de atividades lúdicas, o objetivo era explorar a capacidade criativa dos leitores a partir da experiência que haviam obtido com a leitura da obra. Algumas atividades envolveram vivências artísticas como pintura em tela, música e dramatização.

Como a proposta do clube tratava de (re)apresentar a literatura infantojuvenil a partir de práticas leitoras diferenciadas, um dos critérios de seleção dos títulos foi o da diversidade, motivo pelo qual há livros de formatos, temáticas, organização narrativa e gêneros diferentes. Outra opção importante foi a de fomentar o clube de leitura com obras selecionadas pelo Programa Nacional Biblioteca da Escola (PNBE), cuja chancela marcava vinte e um livros. A esse conjunto agregavam-se mais quatro obras legitimadas por sua qualidade literária por outras agências referentes ao gênero literatura infantojuvenil, como a Fundação Nacional do Livro Infantil e Juvenil (FNLIJ). 
Evidenciava-se, pois, a preocupação com um acervo minimamente referenciado pela crítica especializada como relevante.

Durante os encontros foram oferecidas atividades diferenciadas para estimular a participação dos leitores no diálogo sobre suas impressões de leitura. Para tanto, uma das atividades fixas se baseava em escutar uma experiência de leitura contada pela mediadora. Além disso, como foram dez encontros, tomamos o cuidado de sempre pensar uma forma diferenciada para que o leitor sentisse confiança ao proferir suas impressões, por exemplo, pedindo a cada um deles que escolhessem um personagem com que tivessem se identificado para falar sobre a história; contassem sobre uma cena que lhe tivessem causado impacto; escolhessem uma ilustração e, a partir dela, desenvolvessem o enredo; pensassem em um objeto da história e explicassem sua relação com os acontecimentos; participassem do resgate de brincadeiras da tradição popular - como a "forca" ou a mímica - no intuito de criar um ambiente de interação entre quem conta a história e quem a ouve; entre outras ações que despertassem o interesse nos leitores em compartilhar suas experiências com o livro.

Para criar a identidade do clube de leitura "Viver e tecer histórias", o ambiente ganhou uma caracterização específica: uma tenda, colchonetes, almofadas e uma manta sobre a qual eram expostas, de maneira centralizada, as obras apreciadas. O clube de leitura também contou com um elemento surpresa, a "caixinha de mimos", que trazia, em cada encontro, um mimo diferente - presentes singelos, como uma caneta e uma caderneta personalizadas com o logo do clube, ou um quebra-cabeça produzido a partir da ilustração de um dos livros do clube, entre outros, fazendo referência às leituras ou às ações do clube, com o objetivo de colaborar para a construção do universo de leitura de cada leitor ali envolvido.

O clube de leitura tornou-se, então, um ambiente propício para expressarem mais livremente opiniões e reflexões sobre o próprio ato de ler. Sob essa ótica, pretendeu-se explorar a capacidade criativa dos leitores por meio de atividades lúdicas que se conectassem com as leituras realizadas. Podemos registrar como atividades realizadas ao longo dos encontros, sempre versando sobre a obra lida ao longo da semana: Jogo da memória - produção, em duplas, de um jogo da memória que apresentasse elementos - personagens, locais, expressões, autor, ilustrador; Poema mosaico - produção individual de um poema inspirado na obra ou em partes dela; Ilustrando em tela - ilustração e pintura com material específico como tela de pintura, tinta guache e pincéis, com temas comuns ao texto; Continue a história - criação de uma história coletiva, por meio da oralidade, remetendo o leitor tanto aos textos lidos no clube quanto a outros textos lidos anteriormente; Carta aos autores - os leitores escolheram um dos autores de um dos livros (selecionados para o clube) e redigiram uma carta, a qual, conforme possibilidade, foi enviada ao escritor. O teor da carta era livre, podendo os leitores falar sobre a experiência de leitura, sobre o clube, sobre ter gostado ou não da história; também podiam fazer sugestões aos autores; Painel de indicações de leituras - produto final elaborado pelos leitores do clube: um cartaz contendo a indicação, por meio de propaganda, de um dos livros apreciados no decorrer dos encontros. Os cartazes ficaram expostos em um painel no dia do encerramento dos encontros do clube de leitura; Livro dos livros incríveis - esse livro foi montado com os cartazes produzidos pelos leitores, depois da exposição em painel. Cada cartaz transformou-se em uma das páginas do livro, o qual também contou com informações sobre autores, ilustradores e sobre o próprio leitor criador da "página".

$\mathrm{Na}$ última etapa de cada encontro, o processo criativo era marcado pelo objetivo de instigar os alunos à reflexão sobre a leitura realizada, explorando o imaginário por meio da sensibilidade ao texto verbal, imagético, sonoro. No sétimo 
encontro, por exemplo, foi apresentada a proposta da produção de um "poema mosaico". A intenção era de que, a partir da experiência de leitura, os leitores produzissem um poema inspirado no livro escolhido para a leitura daquela semana. Para isso, em cada caixinha de mimo foi disponibilizado um material - um bloquinho com dez papéis personalizados -, para que, em cada um deles, os leitores escrevessem uma palavra do poema produzido por eles mesmos. Sendo assim, se um leitor escrevesse os seguintes versos: "No céu da minha vida / brilha uma intensa estrela vermelha", cada palavra era escrita em um dos papéis. Como no exemplo:

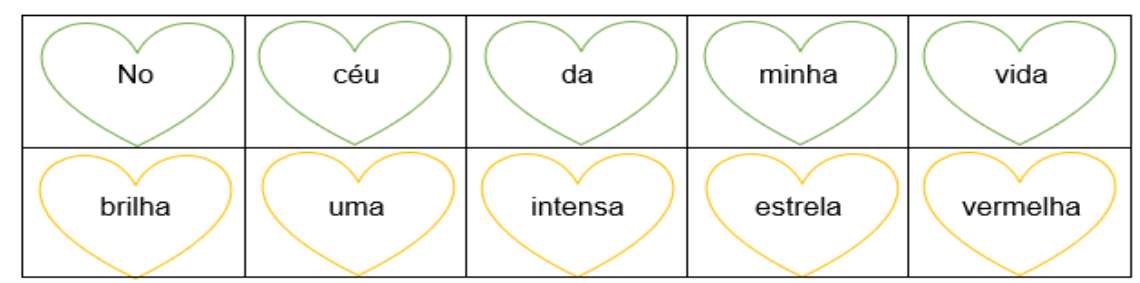

Fig. 1: Exemplo para a produção do poema mosaico

Com esse procedimento realizado, cada papel recebia um imã em seu verso para ser colocado em qualquer estrutura de metal, um painel ou na geladeira, por exemplo. Nesse formato, o poema poderia ser mantido em sua estrutura original ou ser modificado por qualquer pessoa formando uma nova produção. Um poema mosaico interativo. Vale salientar que os leitores produziram os poemas individualmente, no entanto, durante todo o processo de produção mostraram um espírito de equipe. Alguns leitores cederam os papéis que não utilizaram para aqueles que se empolgaram e precisaram de mais papéis para terminar seus poemas.

Como exemplo, registramos dois textos produzidos pelos membros do clube:

(1)

A lua ilumina a rua
soldado algemado na sombra escura
imediatamente e rapidamente
procura seguro
uma república em Vila Rica
procurando atravessando e caminhando
vou andando em frente.

(2)

O perfume intenso das flores

É o borbulhar intenso dos mares

a combinação perfeita para $o$

nascimento de uma bela cinderela.

A primeira produção foi inspirada na obra Dirceu e Marília, de Nelson Cruz (2008); a segunda inspirada no mito "O nascimento de Vênus", do livro Deuses heróis e monstros, de A. S Franchini e Carmen Seganfredo (2009) - percebemos, em ambos os textos, a sensibilidade no que diz respeito à escolha vocabular e ao intertexto, com destaque, na segunda produção, para o tradicional conto de fadas "Cinderela". Consideramos, portanto, que essas elaborações ajudam a pensar que seus criadores, possivelmente por estarem mais íntimos da leitura literária, sentiram-se seguros para o processo do "fazer literário" e, assim, produzirem algo com maior elaboração 
linguística, indicando o amadurecimento, como leitores, na busca de estabelecer elementos intertextuais.

As atividades planejadas para a etapa dos encontros também foram concebidas com o intuito de trabalhar aspectos como a materialidade do livro, seus elementos paratextuais, suas ilustrações ou projeto gráfico. No quinto encontro, por exemplo, o livro apresentado para iniciar as atividades do dia foi Um verso a cada passo: a poesia na estrada real, da escritora Angela Leite de Souza (2009). Recorrendo à ilustração peculiar da obra, foi contado um pouco sobre a história "por trás da história", isto é, sobre o contexto histórico que inspirou Ângela a criar aquele texto. A reação dos leitores às ilustrações foi encantadora, pois os alunos demonstraram intensa relação com as imagens formadas a partir de retalhos de tecidos, com bordados e pedrarias. Para finalizar a apresentação do livro com a intenção de oferecer um contato mais concreto com a poesia oferecida por ele e, logo, seguir com as orientações, foi realizada a leitura da primeira poesia.

Logo, o encontro seguiu a partir das seguintes orientações aos leitores: 1) encontrar o nome do ilustrador; 2) folhear novamente as páginas do livro e escolher uma das ilustrações que mais lhes chamara a atenção; 3) apresentar a ilustração e suas impressões sobre ela no momento da "roda de histórias".

O momento mais impactante do encontro foi quando os leitores começaram a se organizar para seguir as etapas dessas orientações, visto que iniciaram um diálogo entre si, um mostrando para o outro as ilustrações dos seus livros, uns ajudando aos outros a encontrarem o nome do(a) ilustrador(a). Dessa maneira, os leitores iniciaram de forma autônoma a roda de histórias, mesmo sem muita organização - falando todos de uma vez, um atravessando o diálogo do outro, porém, eles próprios tentavam mediar seus momentos de voz. Era possível perceber, nessa busca de autodeterminação, segurança e entusiasmo por parte dos leitores infantis.

Todos participaram da atividade. Alguns leitores limitaram-se a mostrar as imagens escolhidas e a falar um pouco sobre as cores. Outros avançaram em suas exposições - mostraram a ilustração, comentaram sobre as cores, sobre os traços, associaram a história às imagens, demonstrando que perceberam uma relação de complementaridade entre ambos.

Outra atividade que pode melhor dimensionar a relação que os leitores passaram a estabelecer com a leitura literária foi a produção de uma carta, a qual teria como remetente o leitor do clube e como destinatário um dos autores de um dos livros lidos nos encontros anteriores. Por isso, o mimo do dia foi um papel de carta personalizado com as cores e o logo do clube. A orientação repassada sobre o teor da carta indicava que os leitores poderiam escrever sobre o assunto que quisessem, mas que, em algum momento deveriam comentar seus sentimentos, impressões, sugestões e/ou críticas em relação à obra do autor que haviam escolhido. A intenção era enviar realmente as cartas e a expectativa era de que alguns dos autores pudessem respondêlas.

As cartas foram escritas e, conforme a possibilidade, enviadas. Foi um trabalho intenso entrar em contato com os autores. A maioria estava acessível por meio da rede social Facebook. Conseguimos conversar sobre o projeto com os escritores Luis Dill, Daniel Munduruku, Angela Leite de Souza, Ana Tortosa, Ricardo Azevedo, Marco Haurélio, Leo Cunha e André Neves. Todos foram muito prestativos e passaram o endereço eletrônico ou o endereço de suas casas. Aos que passaram o endereço da casa, enviamos as cartinhas pelo correio; aos que passaram o endereço de e-mail, enviamos as cartinhas digitalizadas. 
Os escritores Marco Haurélio, Ricardo Azevedo e Angela Leite de Souza receberam as cartinhas em suas casas e responderam da maneira mais atenciosa possível, enviando, também, livros autografados aos leitores. Os escritores Luis Dill, Daniel Munduruku e André Neves e a escritora Ana Tortosa responderam via e-mail.

A atividade referente à escrita das cartas aos autores provavelmente foi uma das que mais impactaram os participantes, pois o retorno foi surpreendente. Receber em casa livros autografados ou cartas dos próprios autores foi uma experiência importante para que eles pudessem estabelecer uma relação mais próxima, e positiva, com aqueles que produzem as histórias que haviam lido. Muitos leitores consideravam que os autores ou não existiam, ou já estavam mortos. Os autores que, antes, pouco eram mencionados, passaram a ser encarados como figuras "presentes" durante as atividades. Nomes que passaram a representar de modo mais significativo pessoas num contexto social ao qual nossos leitores podiam se ver vinculados.

\section{Considerações finais}

Luzia de Maria (2009), vinte anos depois de seu clube de leitura, em um reencontro com seus ex-alunos, tem a oportunidade de ouvir e registrar vários relatos de ex-alunos que participaram do clube do livro. Os (ex-)alunos apresentaram à professora suas memórias de leitura e como a experiência proporcionada naquela época refletiu positivamente em suas vidas, fosse em aspectos profissionais, fosse em desenvolvimento pessoal. Os relatos revelam os bastidores, o cotidiano, as experimentações diversas, o romper e o surgir de expectativas em relação à literatura e ao processo de formação do leitor perene por meio de um clube de leitores. Diante desse cenário, Luzia de Maria conclui:

A diferença estava ali, visível. O que me emocionou e me impressionou mais - naquele e em nossos contatos posteriores - foi reconhecer que a terra era boa e o que foi plantado, enraizou: todos eles são cultos, são leitores, são profissionais bem-sucedidos, seguramente tiveram uma ascensão social, muitos não se restringiram a uma graduação, fizeram pós, mestrado e doutorado. E todos continuam experimentando a "felicidade de ser leitor". Não foi possível contatar todos da turma, mas o que temos aqui é uma boa amostra do que pode uma escola pública. Com livros, com literatura, com leitura e com seriedade e paixão se faz cidadania plena! (MARIA, 2009, p. 240)

O clube do livro foi uma ação de fomento à leitura que fez valer a função primeira da escola de formar o leitor com vistas à sua identidade e integridade cidadã. Os alunos leitores tornaram-se cidadãos leitores e, conforme relatos dos ex-alunos, também, mediadores de leitura em suas casas. Estabeleceu-se uma (re)ação em cadeia.

Em uma perspectiva similar, o clube de leitura "Viver e Tecer Histórias" funcionou como um suporte para a oferta de um espaço democrático tendo em vista o legítimo encontro entre o leitor e a leitura de literatura. Entre a fala acalorada de uns e a observação tímida de outros, os participantes tiveram vez e voz e todos, pouco ou muito, teceram comentários, pelo menos uma vez, sobre os livros, ratificando afirmação de Regina Zilberman (2014, p. 267) “o texto literário, porque produz algum tipo de satisfação, pode levar seu usuário a falar ou a calar, mas nunca o deixa indiferente". 
Almejou-se criar um ambiente do encontro das percepções sobre o real e o ficcional, dos intertextos, da transfiguração das ideias, para que outras formas de pensar o mundo pudessem ser suscitadas nos jovens leitores em formação.

Dessa forma, podemos dizer que a implantação do clube de leitura, no contexto da E. E. Professora Isabel Cristina Fávaro Palma, no município de Tejupá - SP, veio ao encontro dos princípios discutidos acerca da escolarização adequada da literatura, principalmente a denominada infantojuvenil, visto que, aliando pressupostos teóricos às práticas pedagógicas, buscou sistematizar ações que centralizaram a leitura do texto literário na sala de aula, respeitando sua natureza específica e cultivando leitores mais atentos às trilhas da literatura.

\section{Referências}

AGUIAR, V. T.; BORDINI, M. da G. Literatura: a formação do leitor (alternativas metodológicas). Porto Alegre: Mercado Aberto, 1988.

BALSAN, S. F. de S. Nas veredas da leitura: ações para a formação de leitores autônomos. Presidente Prudente, 2018. 257p.Tese (Doutorado) - Faculdade de Ciências e Tecnologia, Campus de Presidente Prudente, Universidade Estadual Paulista.

CECCANTINI, J. L. Leitores iniciantes e comportamento perene de leitura. In: SANTOS, F.; MARQUES NETO, J. C.; ROSING, T. M. K. (Org.). Mediação de leitura: discussões e alternativas para a formação de leitores. São Paulo: Global, 2009, v. 1, p. 207-231.

COSSON, R. Letramento Literário: teoria e prática. São Paulo: Contexto, 2016.

FERREIRA, E. A. G. R. Construindo histórias de leitura: a leitura dialógica enquanto elemento de articulação no interior de uma biblioteca vivida. Assis, 2008. 300p. Tese (Doutorado em Letras) - Faculdade de Ciências e Letras, Campus de Assis, Universidade Estadual Paulista "Júlio de Mesquita Filho".

FERREIRA, E. A. G.; VALENTE, T. A relação afetiva com a leitura: memórias de professores. Revista Profissão Docente, Uberaba, v.12, n. 26, p.5-25, jan/jun. 2012.

LAJOLO, M. O texto não é pretexto. In: ZILBERMAN, R (Org.) Leitura em crise na escola. Porto Alegre: Mercado Aberto, 1982.

MARIA, L. de. O Clube do livro: ser leitor - que diferença faz? São Paulo: Globo, 2009.

MELlO, C. J. de A.; HIDALGO, A. M.; LIRA, A. C. M. Formação do leitor como proposta pedagógica: literatura infantil e comportamento perene de leitura. In: Signo. Santa Cruz do Sul, v. 36 n.60, p. 02-16, jan.-jun., 2011. Disponível em: http://online.unisc.br/seer/index.php/signo/index Acesso em: 17 jul. 2019.

Recebido em 05 de agosto de 2019

Aceito em 29 de outubro de 2019 
